\title{
Pseudoangiomatous stromal hyperplasia of the breast presenting as gigantomastia: case report
}

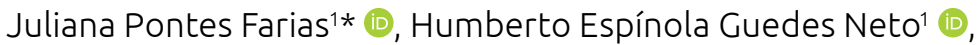 \\ Ariano Brilhante Pegado Suassuna ${ }^{1}$ (D), Rafael Chaves Claudino de Queiroga ${ }^{10}$, \\ Arthur Antonino da Silva Nunes ${ }^{1}$ (D) Adriano de Lima Quirino ${ }^{10}$, Thaíse Lopes Medeiros ${ }^{1}$
}

\section{ABSTRACT}

Pseudoangiomatous stromal hyperplasia (PASH) of the breast is a benign condition generally seen as an incidental finding of biopsies for other causes. In some rare cases, it can evolve with expressive growth of breast tissue, leading to large breasts. The present study presents a case report of a patient who started with breast hypertrophy during lactation, evolving with gigantomastia, and arrived at the office 3 years after gestation with breasts of 6.2 and $4.3 \mathrm{~kg}$ and growth of accessory breast and axillary lymph nodes. The patient was emaciated, with bodily pain and psychological distress. Computed tomography was performed with the finding of diffuse retroglandular nodules and axillary and mediastinal lymph node enlargement, without being able to rule out the lymphoproliferative process. Then, core biopsies were made in several places on the breast whose pathological examination revealed PASH samples. Bilateral mastectomy was performed as a surgical treatment, with resection of the left accessory breast and left axillary lymph node, and breast reconstruction, with placement of silicone prostheses and graft of the areola-papillary complex, together with a plastic surgeon. She evolved in the postoperative period with good healing of the surgical wound, weight gain, necrosis of the areola-papillary complex and with severe psychiatric disorder, which was treated appropriately by psychiatrists, with remission of symptoms. This case report presents a rare evolution of PASH with gigantomastia, bringing intense physical and psychological distress to the patient, whose treatment chosen was total surgical resection of the breast tissue and aesthetic reconstruction.

KEYWORDS: breast neoplasms; breast implantation; lactation; mastectomy; pathology.

\section{INTRODUCTION}

Pseudoangiomatous stromal hyperplasia (PASH) is a rare benign condition of the breasts first described in $1986^{1}$, most commonly found in women in pre- and perimenopause ${ }^{2}$ with findings on imaging tests not specific to this condition, requiring a correlation with the anatomopathological aspect for diagnostic confirmation $^{3}$. PASH can coexist with other breast lesions or even mimic fibroadenoma and it can progress, in spite of its being a benign disease ${ }^{4}$. The diagnosis of this condition usually occurs incidentally during investigation with anatomopathological study of other benign or malignant diseases of the breast ${ }^{5}$. Treatment varies depending on the presentation.

The objective of this study was to report a case with atypical evolution and surgical treatment with bilateral mastectomy and immediate reconstruction, since the patient presented a rare and diffuse PASH condition beginning in pregnancy with rapid and bilateral breast enlargement.

\section{CASE REPORT}

A 27-year-old woman was referred to the outpatient mastology service at the Hospital Universitário Lauro Wanderley (HULW), in João Pessoa, Brazil, with the complaint of bilateral gigantomastia accompanied by weight loss. She was seen for the first time in August 2019, reporting breast enlargement that started during pregnancy (three years ago) and worsened during lactation.

After the first consultation, the patient did not attend the return visit and only in February 2020 did she return to the clinic for further investigation. The breasts had almost doubled in size compared to the first consultation, with engorged vessels and areas with necrosis and suppuration (Figure 1). Diagnostic hypotheses were raised for PASH and breast lymphoma, both rare conditions. Malignant neoplasm was considered due to rapid growth, the presence of axillary lymph node enlargement and significant weight loss. Complementary investigation did not include mammography due to the patient's age and, mainly, due to the

\footnotetext{
${ }^{1}$ Hospital Universitário João Pessoa, Universidade Federal da Paraíba - João Pessoa (PB), Brazil.

*Corresponding author: juliana_pontesfarias@yahoo.com.br

Conflict of interests: nothing to declare.

Received on: 10/04/2020. Accepted on: 11/09/2020.
} 


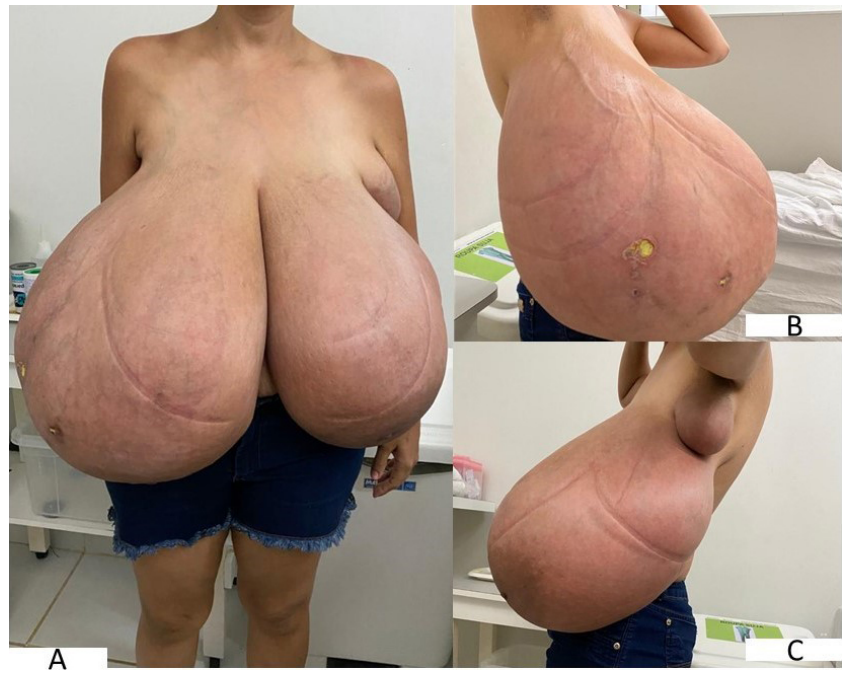

Figure 1. (A) Front view of the breasts; (B) right breast in lateral view, with suppurative ulcer; (C) left breast in lateral view and accessory breast (photographs taken in February 2020). impossibility of performing it in view of the technical limitations given the expressive size of the breasts. On the day of the consultation, a computed tomography (CT) scan of the chest was performed, with and without iodinated venous contrast, revealing an important volumetric increase in the breasts due to the multiple confluent nodular formations, predominantly retroglandular, which exhibited slight impregnation by means of contrast, of etiology indeterminate to the method, and it was not possible to discard a lymphoproliferative process. The presence of multiple lymph node enlargement in axillary chains and in the internal chest wall bilaterally also stands out (Figures $2 \mathrm{~A}$ and 2B). A laboratory screening with general exams and serology was requested to rule out associated conditions and to obtain the necessary exams for surgery.

Fragments of the left breast were also collected by means of a core-biopsy for histopathological analysis. The result was released on February $10^{\text {th }}, 2020$, revealing breast tissue with pseudoangiomatous stromal hyperplasia (morphological aspects
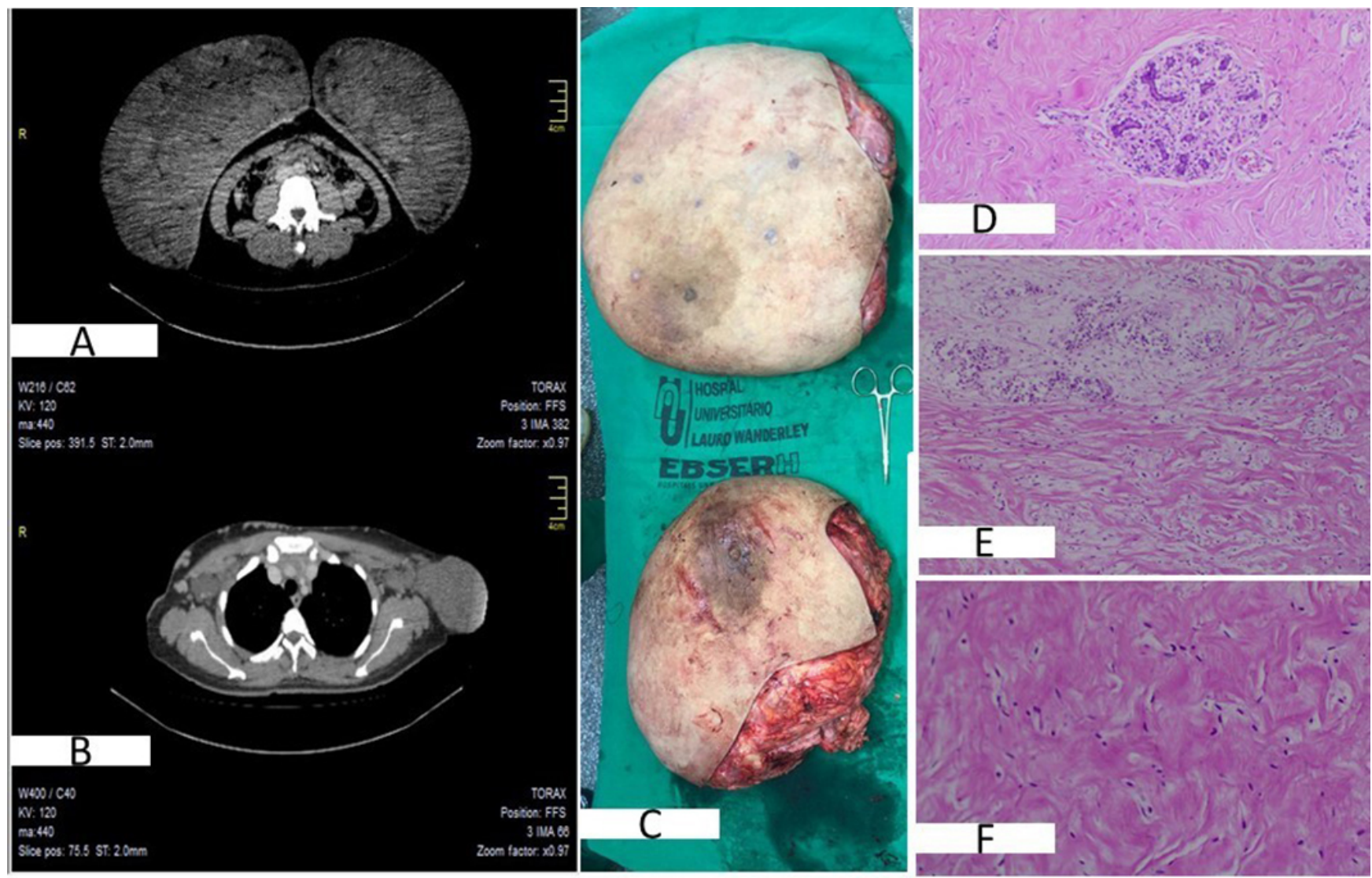

Figure 2. (A) Chest computed tomography shows a volumetric increase in the breasts due to multiple confluent nodular formations, predominantly retroglandular; (B) chest computed tomography highlighting the presence of multiple lymph node enlargements in axillary chains and the presence of the accessory breast on the left; (C) surgical parts of the direct and left breast (top to bottom); (D) anatomopathological showing stromal pseudoangiomatous hyperplasia, nodular and diffuse forms; (E) lymph nodes with reactive lymphoid hyperplasia; (F) absence of signs of malignancies. 
consistent with the diffuse form of PASH) and absence of signs of malignancy.

On March $12^{\text {th }}, 2020$, the patient underwent bilateral total mastectomy and immediate breast reconstruction by the services of mastology and plastic surgery, respectively, at HULW. Both breasts, the left accessory breast, and the left axillary lymph nodes were resected (Figures $2 \mathrm{C}$ and $3 \mathrm{~A}$ ). The areola-papillary complex was preserved and used as a graft in the reconstruction of the breasts, and silicone prostheses were implanted in a submuscular position (Figure 3B).

Surgical specimens were sent for histopathological study at the Pathological Anatomy Laboratory (Laboratório de Anatomia Patológica - LAP) of the same hospital (Figures 2D, 2E, and 2F). The results, released on March $26^{\text {th }}, 2020$, were:

- Right breast (weight =6,255 g; dimensions = 38 ×32 $\times 10 \mathrm{~cm}$ ): pseudoangiomatous stromal hyperplasia, nodular and diffuse forms; skin without particularities; absence of signs of malignancy;

- Left breast (weight = 4,295 g; dimensions: $29 \times 27 \times 12 \mathrm{~cm}$ ): pseudoangiomatous stromal hyperplasia, nodular and diffuse; skin without particularities; absence of signs of malignancy;

- Left accessory breast (dimensions $=11 \times 8 \times 5 \mathrm{~cm})$ : ectopic breast tissue with pseudoangiomatous stromal hyperplasia; skin without particularities; absence of signs of malignancy;

- Axillary lymph nodes on the left (dimensions $=2.5 \times 2 \times$ $0.8 \mathrm{~cm}$ ): lymph nodes with reactive lymphoid hyperplasia; absence of signs of malignancy.

In the first postoperative visit, the patient returned without complaints. On physical examination, significant edema was observed in the inframammary folds (Figure 3C). On the second return, she presented remission of these findings and complained of delusions, being referred to the psychiatric service, where drug treatment was started. In the third consultation, she showed improvements in psychiatric symptoms and the removal of the surgical stitches was performed. Partial necrosis of the areola-papillary complex grafts and progressive weight gain, around $15 \mathrm{~kg}$, were observed in relation to the beginning of the follow-up (Figure 3D). The possibility of a corrective surgical procedure was offered, however, the patient expressed no interest in performing a new surgery.

The study was carried out according to the ethical principles of studies in human beings according to the Declaration of Helsinki, with the approval of the Research Ethics Committee of Hospital Universitário Lauro Wanderley, with CAAE number 36548520.2.0000.5183.

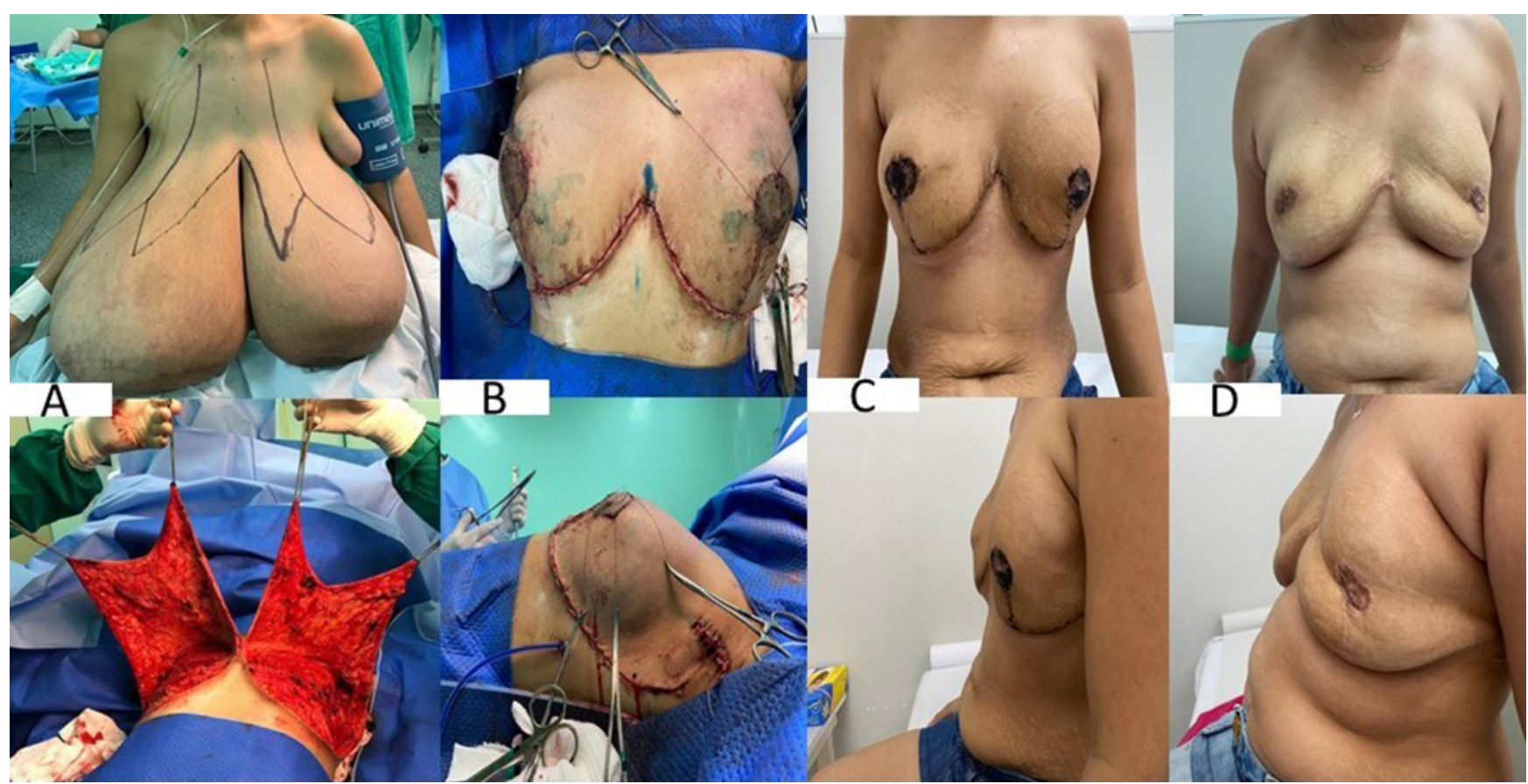

Figure 3. (A) marking and skin flaps after mastectomy; (B) frontal and lateral view of the immediate postoperative period of breast reconstruction after total mastectomy with resection of the left accessory breast; (C) postoperative period of April 2020, showing signs of partial necrosis of the areola-papillary complex grafts; (D) Late postoperative period of September 2020, showing good healing of the surgical wound, in addition to the patient's weight gain. 


\section{DISCUSSION}

PASH is a benign stromal proliferation that can affect different age groups, with a mean age ranging between 37 and 51 years 6 , with up to $75 \%$ of pre-menopausal patients ${ }^{7}$. The patient in this case was affected at a younger age than the average.

The precise etiology of PASH is unknown, but hormones are attributed a role in its development ${ }^{2}$, considering that almost all affected postmenopausal women were using hormone ${ }^{8}$.

There are typically two clinical types of PASH - nodular and diffuse. The nodular type is characterized by a unilateral, circumscribed, slow-growing mass and is usually an incidental finding that mimics fibroadenomas. The diffuse type is more rare, with about 20 cases reported in the literature ${ }^{9}$. The involvement of the areola-papillary complex and the axillary accessory breast are also atypical findings ${ }^{10}$. In this respect, the case has unusual characteristics, such as bilateral involvement, diffuse growth, impossibility to delimit the tumor, and the onset of an axillary accessory breast. Only two cases of PASH beginning with pregnancy have been reported ${ }^{9,11}$, as happened in the present study's patient.

A case of axillary lymph node enlargement is described in the literature, probably reactional to edema ${ }^{12}$. The patient in the present case also had a lymph node with reactive lymphoid hyperplasia.

Ultrasonographic findings are variable, ranging from circumscribed to indistinct tumors ${ }^{13}$, more commonly with the presence of a hypoechoic and heterogeneous nodule ${ }^{14}$. A study that evaluated ultrasound findings in patients with PASH classified 93.6\% of the cases as BI-RADS 4, due to the fact that these exams present images with non-circumscribed margins ${ }^{14}$. One year before the appointment, the patient underwent breast ultrasound, in which no nodules or changes had been observed. On mammography, solid, non-calcified and circumscribed nodules are typically found, with focal asymmetry ${ }^{3}$. Most studies do not provide a description of this pathology on $\mathrm{CT}$, therefore, this case proves to be opportune as it presents this characterization.

The main differential diagnoses, due to the clinical or histological aspects of PASH, are: fibroadenoma, phyloid tumor, and low-grade angiosarcoma ${ }^{2,12,14}$. In the present case, diagnostic doubts regarding breast lymphoma were included, due to the presence of weight loss and rapid growth, which was discarded by breast biopsy.

In order to confirm the diagnosis, core-biopsy is sufficient and necessary in cases of abnormal findings on imaging or physical examination ${ }^{4}$. In the case of the patient under study, the tomographic finding did not rule out the presence of lymphoproliferative disease in the breasts, indicating the need for investigative supplementation with a core- biopsy, before scheduling surgical excision.

The management of PASH depends on its presentation ${ }^{8}$. Some studies recommend mastectomy in diffuse type $\operatorname{cases}^{3,4,8}$ and others report $\mathrm{r}^{9,15}$ that immediate breast reconstruction was also performed. The surgical approach of the case is well indicated, in view of the diffuse and rapid growth and its interference in the quality of life.

\section{CONCLUSION}

The present case revealed a rare breast condition with atypical evolution, due to rapid, diffuse, and bilateral progression. Due to the course of the disease in the patient, a surgical procedure for bilateral mastectomy and immediate breast reconstruction with prosthesis implantation was indicated. This experience reinforces the need for good propaedeutic management of PASH and adequate treatment according to the clinical picture presented, especially due to the lack of specific consensus or protocols for the disease. The individualized treatment of each patient is currently the best option, considering clinical evolution, aesthetic aspects, and results of complementary exams.

\section{AUTHORS' CONTRIBUTIONS}

J.P.F.: supervision, methodology, writing - review.

H.E.G.N.: methodology, writing - original draft \& editing. A.B.P.S.: methodology, writing - original draft \& editing. R.C.C.Q.: methodology, writing - original draft \& editing. A.A.S.N.: methodology, writing - original draft \& editing. T.L.M.: methodology, writing - review \& editing. A.L.Q.: methodology, review.

\section{REFERENCES}

1. Vuitch MF, Rosen PP, Erlandson RA. Pseudoangiomatous hyperplasiaofmammarystroma.HumPathol.1986;17(2):185-91. https://doi.org/10.1016/s0046-8177(86)80292-1

2. Smilg P. Pseudoangiomatous stromal hyperplasia: Presentation and management - a clinical perspective. SA J Radiol. 2018;22(2):1366. https://dx.doi.org/10.4102\%2Fsajr.v22i2.1366

3. Raj SD, Sahani VG, Adrada BE, Scoggins ME, Albarracin CT, Woodtichartpreecha $P$, et al. Pseudoangiomatous
Stromal Hyperplasia of the Breast: Multimodality Review With Pathologic Correlation. Curr Probl Diagn Radiol. 2017;46(2):130-5. http://doi.org/10.1067/j. cpradiol.2016.01.005

4. Yoon KH, Koo B, Lee KB, Lee H, Lee J, Kim JY, et al. Optimal treatment of pseudoangiomatous stromal hyperplasia of the breast. Asian J Surg. 2020;43(7):735-41. https://doi. org/10.1016/j.asjsur.2019.09.008 
5. Powell CM, Cranor ML, Rosen PP. Pseudoangiomatous Stromal Hyperplasia (PASH). Am J Surg Pathol. 1995;19(3):270-7.https:// doi.org/10.1097/00000478-199503000-00004

6. Hoda SA, Brogi E, Koerner FC, Rosen PP. Rosen's Breast Pathology. $4^{\text {th }}$ ed. Philadelphia: Wolters Kluwer Health/ Lippincott Williams Wilkins; 2014. 1379 p.

7. Bourke AG, Tiang S, Harvey N, McClure R. Pseudoangiomatous stromal hyperplasia causing massive breast enlargement. BMJ Case Rep. 2015;2015:bcr2014204343. https://doi.org/10.1136/ bcr-2014-204343

8. Nascimento TC, Djahjah MC, Carneiro AHPC, Oliveira AC de, Marchiori E. Pseudoangiomatous stromal hyperplasia presenting as a tumor. Radiol Bras. 2019;52(2):128-9. https:// doi.org/10.1590/0100-3984.2017.0135

9. Krawczyk N, Fehm T, Ruckhäberle E, Mohrmann S, Riemer J, Braunstein S, et al. Bilateral Diffuse Pseudoangiomatous Stromal Hyperplasia (PASH) Causing Gigantomastia in a 33-Year-Old Pregnant Woman: Case Report. Breast Care. 2016;11(5):356-8. https://doi.org/10.1159/000450867

10. Virk RK, Khan A. Pseudoangiomatous Stromal Hyperplasia: An Overview. Arch Pathol Lab Med. 2010;134(7):1070-4. https:// doi.org/10.1043/2008-0686-RS.1
11. Prichard RS, O’Neill CJ, O’Hara JL, Atmore BB, Hassall M. Pseudoangiomatous stromal hyperplasia of the breast: an unusual pathology necessitating bilateral mastectomy during pregnancy. ANZ J Surg. 2011;81(4):304-5. https://doi. org/10.1111/j.1445-2197.2011.05688.x

12. Tsuda B, Kumaki N, Ishida R, Sakaeda E, Ishii S, Mizuno M, et al. Rare finding of bilateral pseudoangiomatous stromal hyperplasia of the breast: A case report. Tokai J Exp Clin Med. 2019;44(4):73-9.

13. PolgerMR,Denison CM,LesterS,MeyerJE.Pseudoangiomatous stromal hyperplasia: mammographic and sonographic appearances. Am J Roentgenol. 1996;166(2):349-52. https://doi. org/10.2214/ajr.166.2.8553945

14. Amorim HLE, Torres AF, Macedo Filho MAA, Paz AR, Pereira GCG. Análise dos achados ecográficos em nódulos de hiperplasia pseudoangiomatosa do estroma mamário diagnosticados por core biópsia. Rev Bras Mastol. 2011;21(2):66-9.

15. Soares AB, Queiroga RC, Soares BR, Maximiano AMC, Cardoso IF, Leal PR. Reconstrução mamária imediata após ressecção de hiperplasia estromal pseudoangiomatosa em adolescente de 13 anos. Rev Bras Mastol. 2011;21(3):127-30. 